\title{
DETERMINATION OF HYDRODYNAMIC COEFFICIENTS OF OBLIQUE TOWING TEST OF A HIGH-SPEED BOAT BY COMPUTATIONAL FLUID DYNAMICS
}

\author{
MOHSEN MAHDAVINIAKI \& MOHSEN BAGHERZADEH
}

Department of Maritime Engineering, Amirkabir University of Technology, Tehran, Iran

\begin{abstract}
An accurate equation-based method can be utilized to investigate the maneuverability of a high speed boat to reduce the cost and time of simulations. However, the accuracy of the equation based method depends on the accuracy of hydrodynamic coefficients of maneuvering equations. These coefficients can be calculated using experimental and numerical methods. In this study, the oblique towing test (OTT) is conducted using computational fluid dynamics (CFD) approach for a boat in two drift angles where two damping coefficients Yv and Nv are extracted. The boat is considered free in heave, pitch and roll motions and the overset grid technology is used to avoid the grid distortion in large variations in heave, pitch and roll motions. For the validation purposes, the calculated force coefficients, yaw moment coefficient, dynamic trim, heel angles and the dynamic sinkage are verified experimental results.

KEYWORDS: Oblique Towing Test (OTT), High Speed Boat, Computational Fluid Dynamic (CFD), Hydrodynamic Coefficients
\end{abstract}

Received: Jun 08, 2020; Accepted: Jun 28, 2020; Published: Sep 30, 2020; Paper Id.: IJMPERDJUN20201458

\section{INTRODUCTION}

The precise prediction of maneuverability of a boat depends on determination of hydrodynamic coefficients. These coefficients are inherent characteristics of a boat. In a preliminary design phase, to investigate the stability and controllability of a boat, these coefficients must be calculated to deliberate if the stability and controllability criteria are satisfied, and if not, they should be satisfied by changing the main particulars of the boat.

There are various methods to estimate hydrodynamic coefficients of the boats such as, experimental model test, numerical simulation and theoretical method. Experimental model test methods are including Oblique Towing Test, Rotating Arm Test and Planar Motion Mechanism. The model test is usually carried out upon the similarity of Froude number. The magnitudes of hydrodynamic coefficients depend on boat's geometry. Using modern sensors in experiments conducted in towing tanks, is one of the accurate methods for estimating these coefficients. 
In 1999, Katayama et al. tested a model with a length to beam ratio of 2.8 with three degrees of freedom (heave, pitch and roll) and calculated the values of six force coefficients in oblique towing test at Froude number of 2 (Katayama, 1999). In 2004, Katayama calculated the force coefficients of oblique towing test on three models, considering three degrees of freedom (heave, pitch and roll) and observed the changes in longitudinal and lateral resistant forces as well as yaw moment in accordance with Froude number (Katayama, 2004).

In numerical simulation, it should be noted that since some commercial software such as ANSYS-CFX and FLUENT need a vast domain as well as dynamic mesh approach for analysis the boat's maneuverability, they are not practical (Bagherzadeh, 2015). Although, there are some other software such as FLOW3D and STAR-CCM+ which are appropriate for free surface simulations and to somehow can model the boats' maneuver. In 2009 , Javanmardi et al. assessed the maneuverability of a trimaran and investigated the longitudinal and transversal effects of lateral bodies on maneuverability by a developed software (Javanmardi, 2009). In 2008, Jahanbakhsh et al. deliberated a HSC's maneuver using CFD simulation and represented the variation of trim, heave, heading, resistance, velocity and power of the engine over the simulation time (Jahanbakhsh, 2008). In 2014, Bagherzadeh with using the finite volume method (FVM) and considering two degree of freedom (heave and pitch) computed the drag force and the trim angle of a high speed boat in different froude numbers and compared with the experimental test results (Bagherzadeh, 2014). In 2019, Nikoosirat et al. conducted numerical simulation using STAR-CCM+ to simulate the self-running of rotating arm test (RAT) of a high speed boat. The model was free in 6 degree of freedom and the trajectory of rotating was verified in Froude number of 0.74 (Nikoosirat, 2019)(a). Nikoosirat et al. in another study, simulated zig-zag manuvering test of a boat and verified the results by Katayama's experimental results (Nikoosirat, 2019)(b). In 2015, Hajivand et al. carried out the maneuvering tests of DTMB 5512 ship (oblique towing test, rotating arm test and zig-zag test) using OpenFOAM library with diferent solvers to calculated hydrodynamic damping coefficients (Hajivand, 2015). In 2016, Meng et al. investigated numerically the oblique current around a tanker model in shallow and deep water conditions, they also calculated hydrodynamic force, pressure distribution and maneuverability of the vessel (Meng,2016).

In theoretical methods, the added mass coefficients and damping coefficients of 3D hulls are predicted based on the hydrodynamic concepts. Studies around commercial boats are immense in this field, but yet are inadequate for high speed boats. 
In this study, the hydrodynamic coefficients are extracted from the oblique towing test using computational fluid dynamic method. For this purpose, k- $\omega$ turbulence model is used and solved Reynolds averaged Navier-Stokes (RANS) equations. At first, the model's motions are investigated in heave, pitch and roll considering two drift angles. Then, the forces and moment on the body in Surge, Sway and Yaw motions are calculated and compared with the experimental results. Finally, the effects of meshing and overset grid technique on the variations of sway force and yaw moment at different speeds are investigated. $Y_{v}$ and $N_{v}$ are variations of lateral force and moment respectively due to variations of lateral speed of the boat and they are calculated.

\section{EXPERIMENTAL OBLIQUE TOWING TEST}

The oblique towing test is conducted in towing tanks equipped with modern facilities. In this test, longitudinal and lateral forces as well as yaw moment are measured. The model is moved with a constant speed in a towing tank.

The tested model is a planning hull type that its length is 1 meter with 3 degrees of freedom (heave, pitch and roll). The connection point of chariot installation on the model is demonstrated in Figure 1. The intersection of the thrust line with the horizontal line and the intersection of centerline with the perpendicular line through the center of gravity are used to measure the dynamic trim and heel angles.

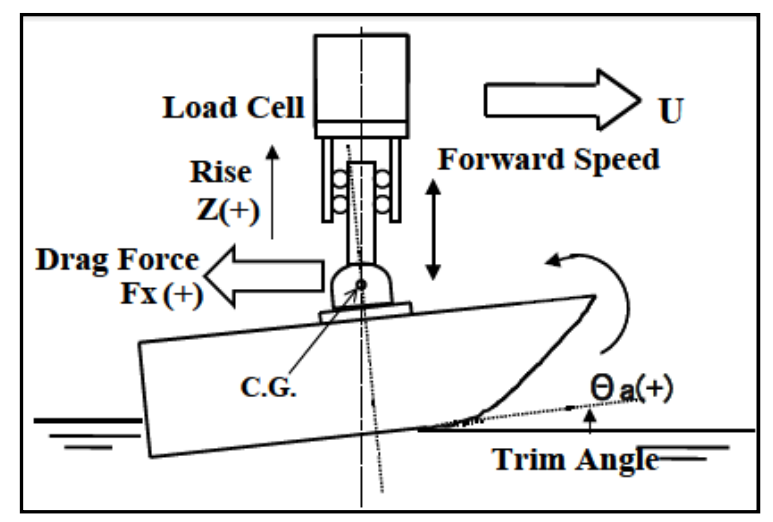

a) Profile veiw

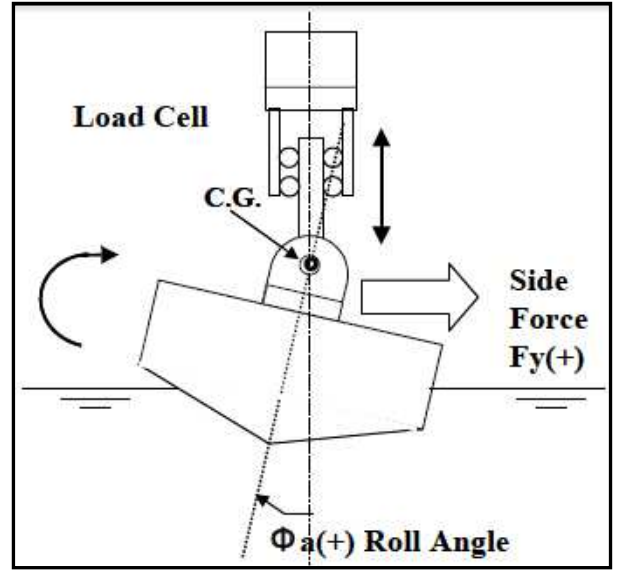

b) Body view 


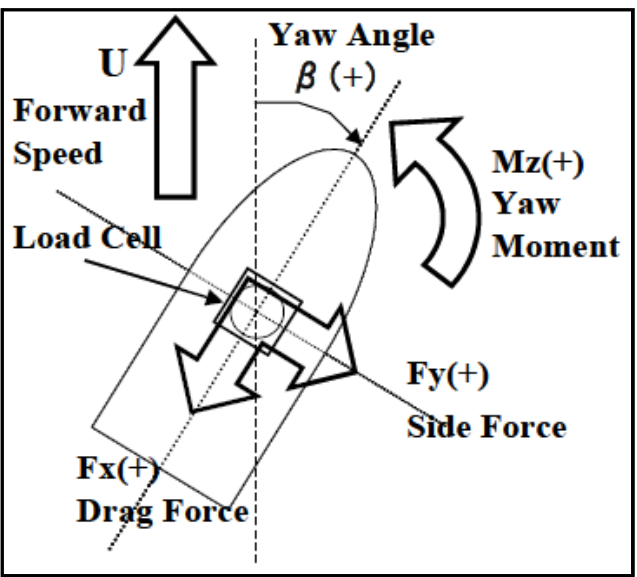

c) Plan view

Figure 1: Connection point of chariot to the model in experimental test. (a) profile view, (b) body view, (c) plan view. (Katayama, 2004).

\section{DYNAMICAL ANALYSIS PROCEDURE}

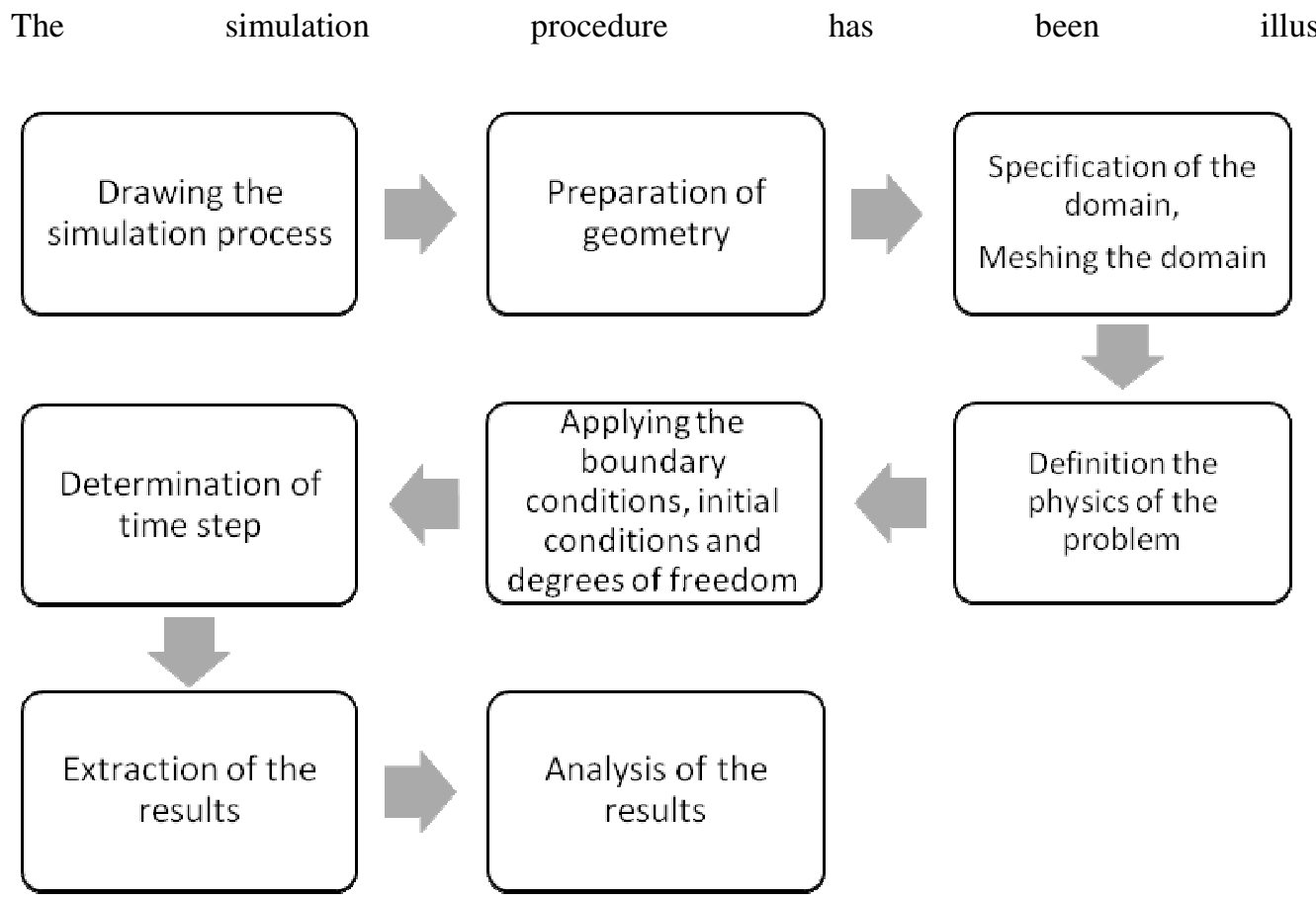

Figure, at first, the geometry of the considered model has been generated by a CAD tool. Since this simulation was supposed to be in accordance with the experimental measurements, three degrees of freedom (heave, pitch and roll) have been considered, and the model has been simulated in its actual size without scaling. The domain size has been determined based on ITTC's CFD suggestions (ITTC, 2011) and hexahedral meshing system has been applied. A two-phased flow (gas-liquid) and VOF technique have been used for free surface simulation. Fluid flow has entered to the domain from the inlet boundary with a velocity equal to the speed of the boat and differentiations in resistance force and the moment have 
been calculated and compared with the results of experimental model tests.

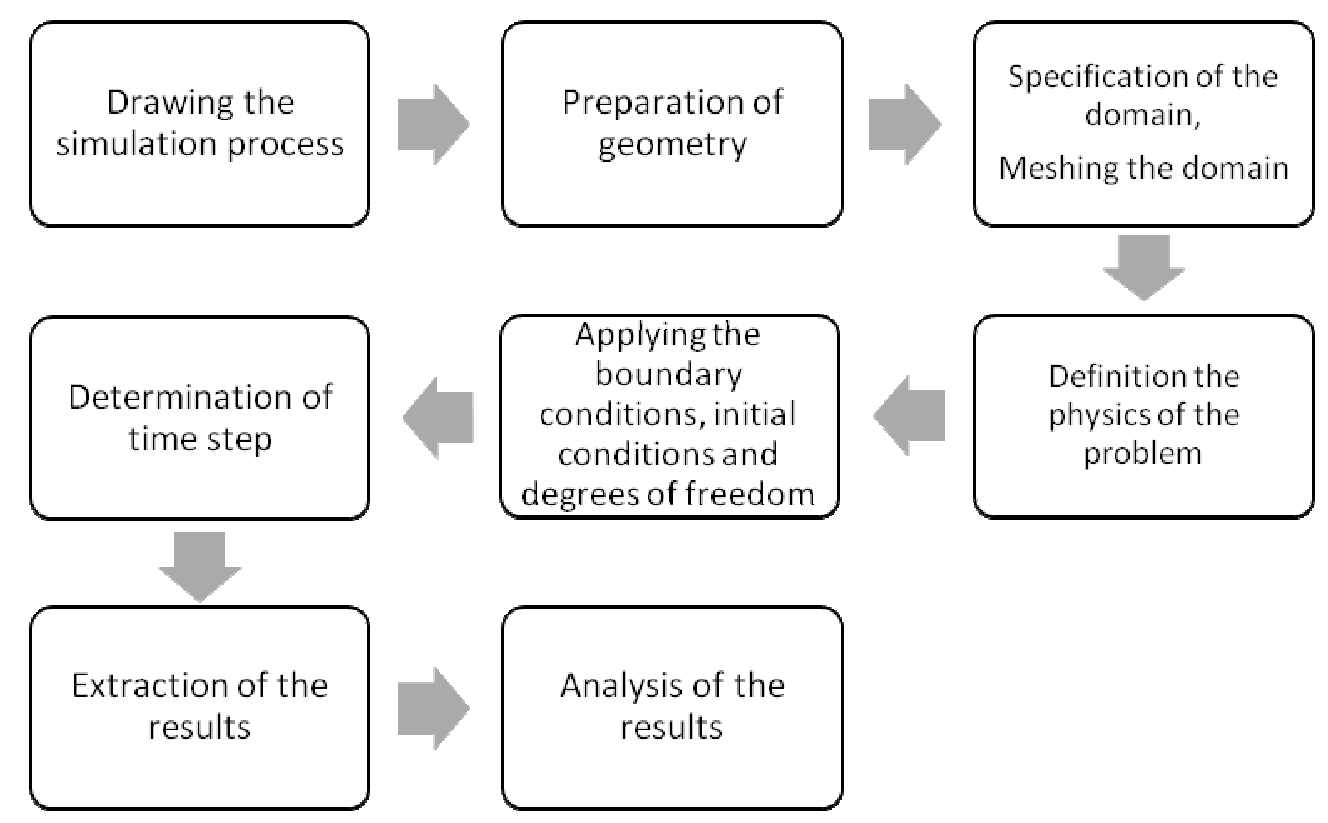

Figure 2: CFD Simulation Procedure

\section{MODEL SPECIFICATIONS}

The used model in this study is one of the proposed models by Katayama on which the oblique towing test were carried out experimentally (Katayama, 2004). Geometrical specifications of this model can be seen in Table 1.

Table 1: Geometrical specifications of the model

\begin{tabular}{|c|c|c|}
\hline Parameter & Value & Unit \\
\hline Model Name & TB45 & - \\
\hline $\mathrm{L}_{\mathrm{OA}}$ & 1 & $\mathrm{~m}$ \\
\hline $\mathrm{B}$ & 0.22 & $\mathrm{~m}$ \\
\hline $\mathrm{D}$ & 0.102 & $\mathrm{~m}$ \\
\hline $\mathrm{T}$ & 0.041 & $\mathrm{~m}$ \\
\hline $\mathrm{M}$ & 3.7 & $\mathrm{~kg}$ \\
\hline$\theta_{0}$ & 0 & degree \\
\hline $\mathrm{V}_{\mathrm{CG}}$ & 0.064 & $\mathrm{~m}$ \\
\hline $\mathrm{L}_{\mathrm{CG}}$ & 0.425 & $\mathrm{~m}$ \\
\hline $\mathrm{S}_{\mathrm{y}}$ & 0.041 & $\mathrm{~m}^{2}$ \\
\hline
\end{tabular}

The length-to-beam ratio of this model is 4.5 and its deadrise angle is 18 degrees. The longitudinal sections of this model are V-Shaped and has one chine. The model is shown in Figure 2. 


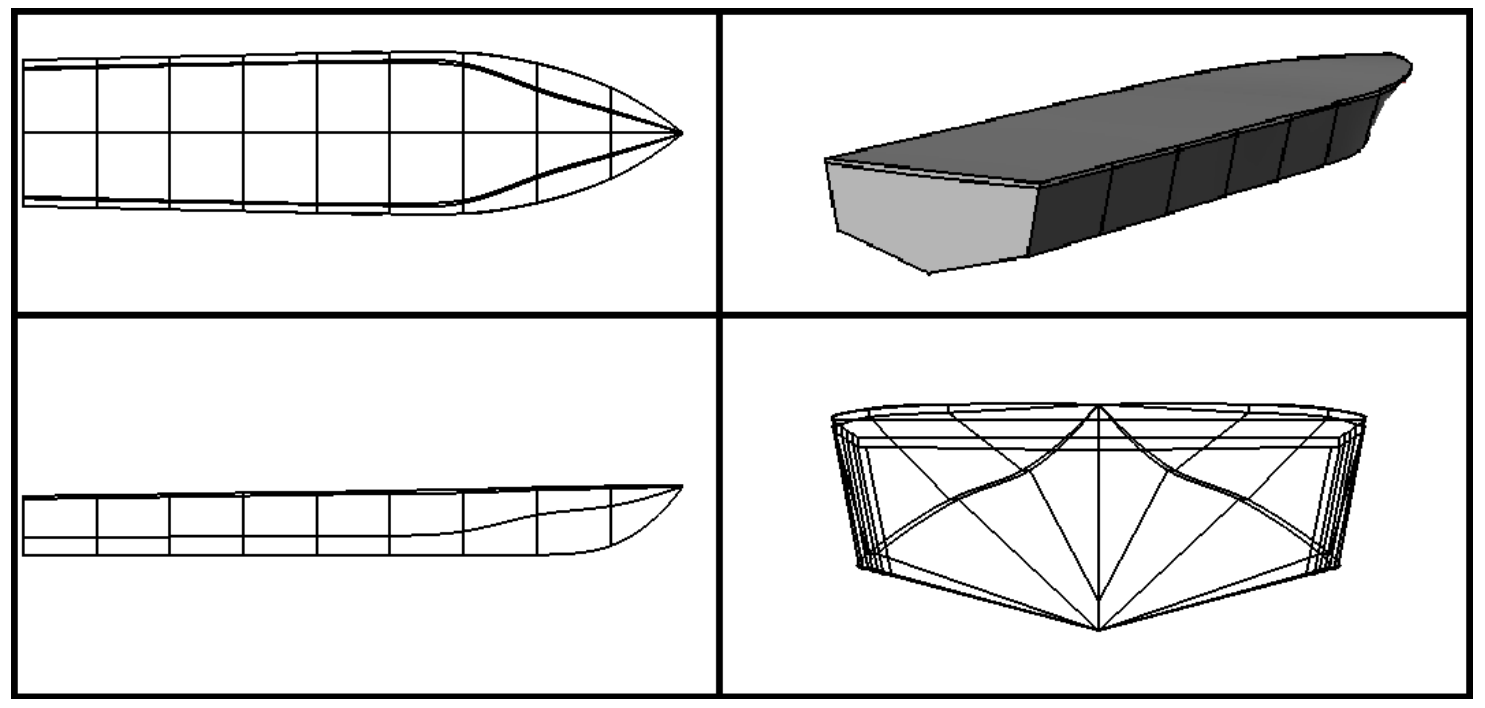

Figure 2: Illustrations of the model TB45

\section{NUMERICAL SIMULATION}

\subsection{The Physical Characteristics of the Problem}

In order to find all hydrodynamic unknown quantities in each time step, the RANS equations are solved using implicit and iterative method. The pressure and velocity parameter were coupled using the velocity-pressure method and whole solution procedure was based on SIMPLE method. The RANS equations have been solved by k- $\omega$ shear stress transport (SST) turbulence model (Marco, 2017). The dynamic fluid body interaction (DFBI) model is defined to simulate the degrees of freedom of the rigid body. By using this model, RANS solver calculates the forces and moments of the boat.

\subsection{Computational Domain}

To model and analyze the flow around the hull, at first the calculation region should be generated surrounding the hull as computational domain. The boundaries of this domain should be far enough from the boat to avoid their effects on the simulations Therefore, based on the recommendations of ITTC's CFD (ITTC, 2011) and also similar studies, the distances of the boundaries have been chosen as shown in Figure 3. 


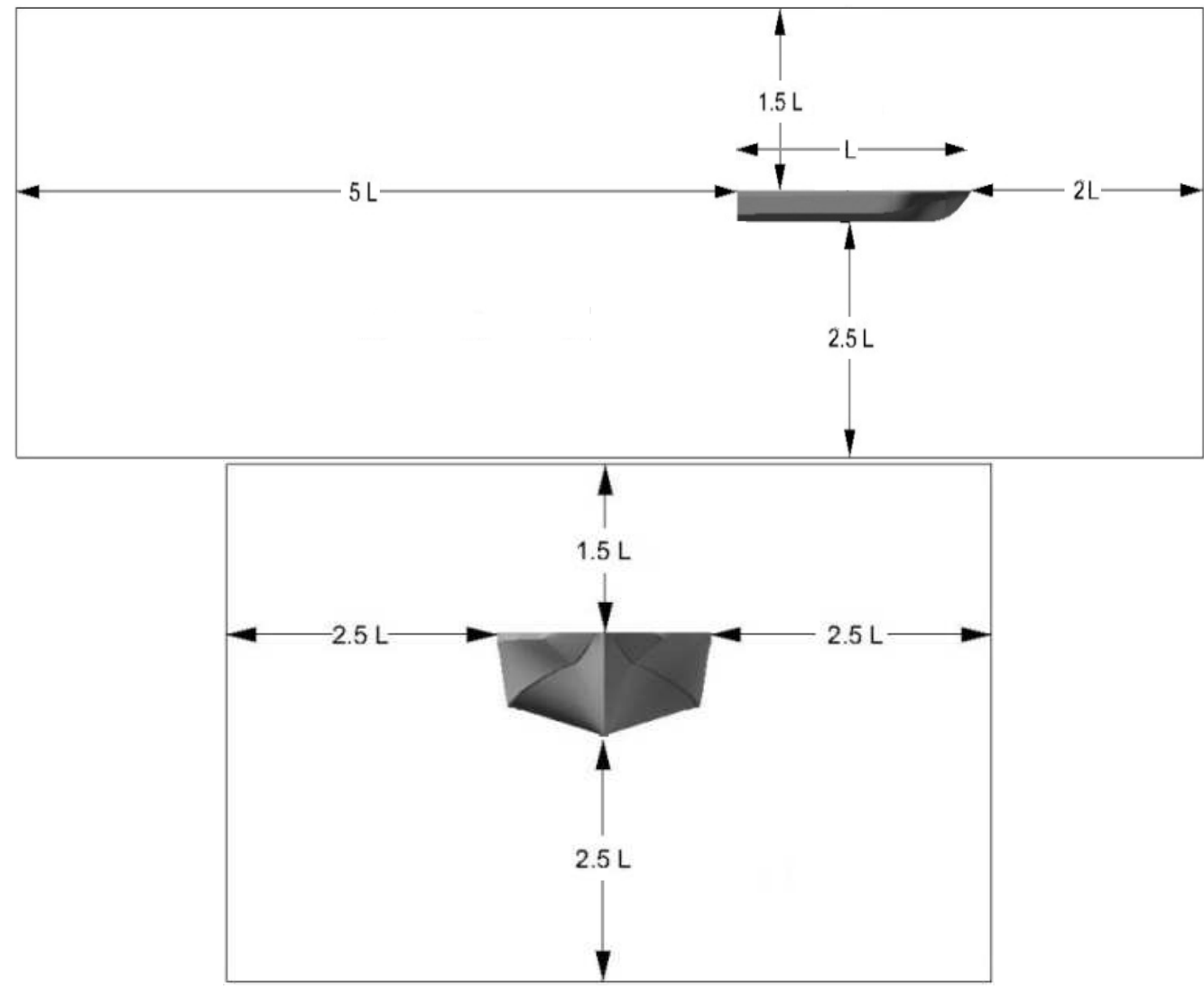

Figure 3 : Computational domain size

\subsection{Meshing}

In Figure 4, a view of generated mesh has been displayed. The mesh elements are finer near the free surface and also around the boat using boundary layer mesh, to enhance the simulation accuracy (Bagherzadeh, a, 2019).

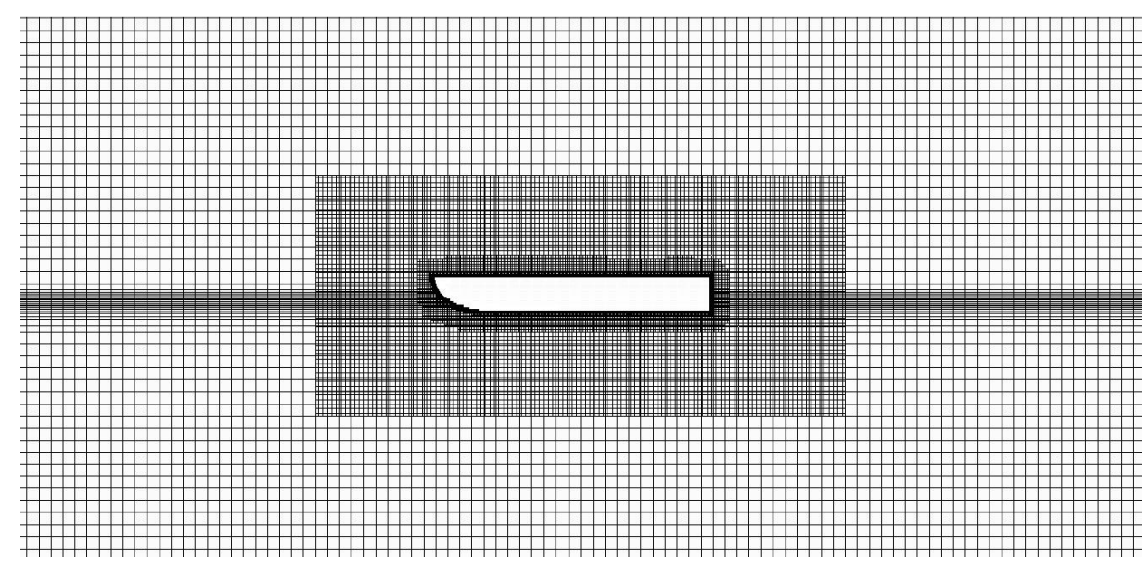

Figure 4: An illustration of computational mesh

The thickness of first layer near the boat was estimated using the following empirical equations: 


$$
\begin{gathered}
R e_{x}=\frac{\rho U L_{O A}}{\mu} \\
\tau_{\text {wall }}=\frac{C_{f} \rho U^{2}}{2} \\
C_{f}=\frac{0.026}{\operatorname{Re}_{x}^{\frac{1}{2}}} \\
U_{\text {fric }}=\sqrt{\frac{\tau_{\text {wall }}}{\rho}} \\
\Delta s=\frac{y^{+} \mu}{U_{\text {fric }} \rho}
\end{gathered}
$$

Then for $\mathrm{y}+<25$ (Figure 5) thickness of the first layer is $10^{-3}(\mathrm{~m})$ and ten layers with a stretching ratio of 1.2 are considered.

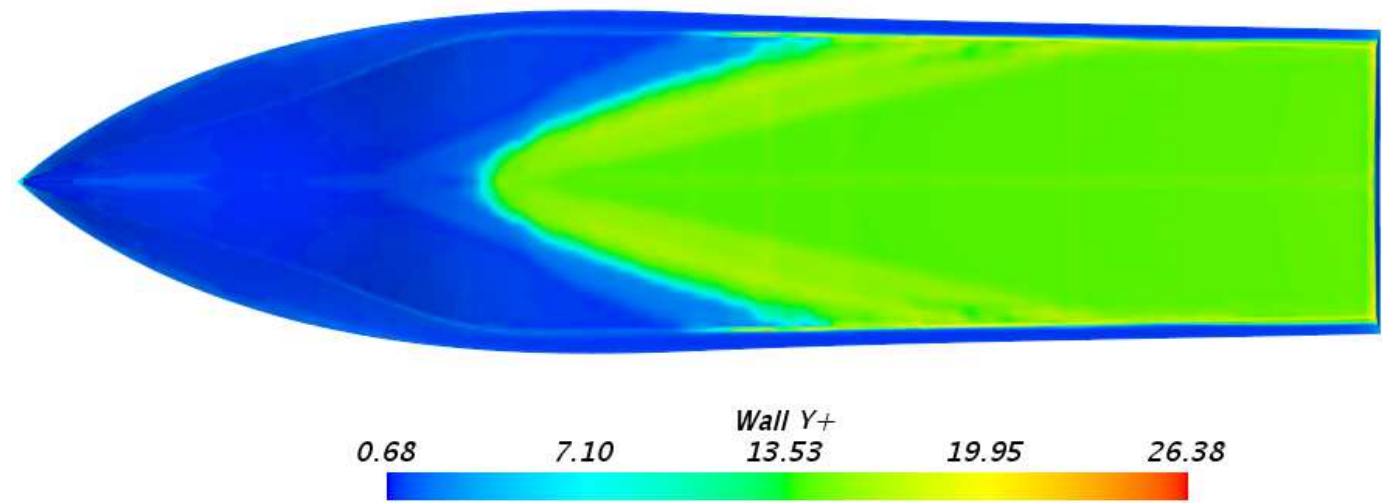

Figure 5: Wall $\mathrm{Y}+$ on the hull at $\mathrm{Fn}_{\mathrm{L}}=1.2$

The mesh specifications and dimension of computational domain are shown in Table 2.

Table 2 : Mesh specifications

\begin{tabular}{|c|c|c|}
\hline Mesh Type & Dimension of the Domain $(\mathbf{m})$ & No. of Elements \\
\hline Hexahedral & $8 \times 5.2 \times 4.8$ & $2,648,000$ \\
\hline
\end{tabular}

The overset and morphing grids methods could be used as dynamic mesh techniques, however, investigation showed that for rapid and high movements of body, overset technique is better than morphing (Marco, 2017). 


\subsection{Time Step}

In implicit simulations, a time step should be determined. Since the time step has significant influence on the accuracy of the results ((Bagherzadeh, b, 2019)) and it has been selected based on ITTC's CFD (ITTC, 2011) recommendation ,where, the time step of a high-speed boat simulation in still water, is a function of length-to-velocity ratio of the model and is determined by equation (6). A minimum of 5 iterations are considered to converge the solution in each time step.

$$
\Delta t=(0.01-0.005) \frac{L_{w l}}{U}
$$

\subsection{Boundary Conditions}

One of the crucial phases of a simulation is selecting suitable boundary conditions. To simulate the model's motions and due to the restrictions on meshing, the boat model is always considered stationary and the current enters the computational domain from the inlet boundary with a velocity equal to the model's speed. Subsequently, the boundary conditions are as shown in Figure 6. These boundary conditions are selected in a way to avoid back flow and lateral boundary effects on the simulation results.

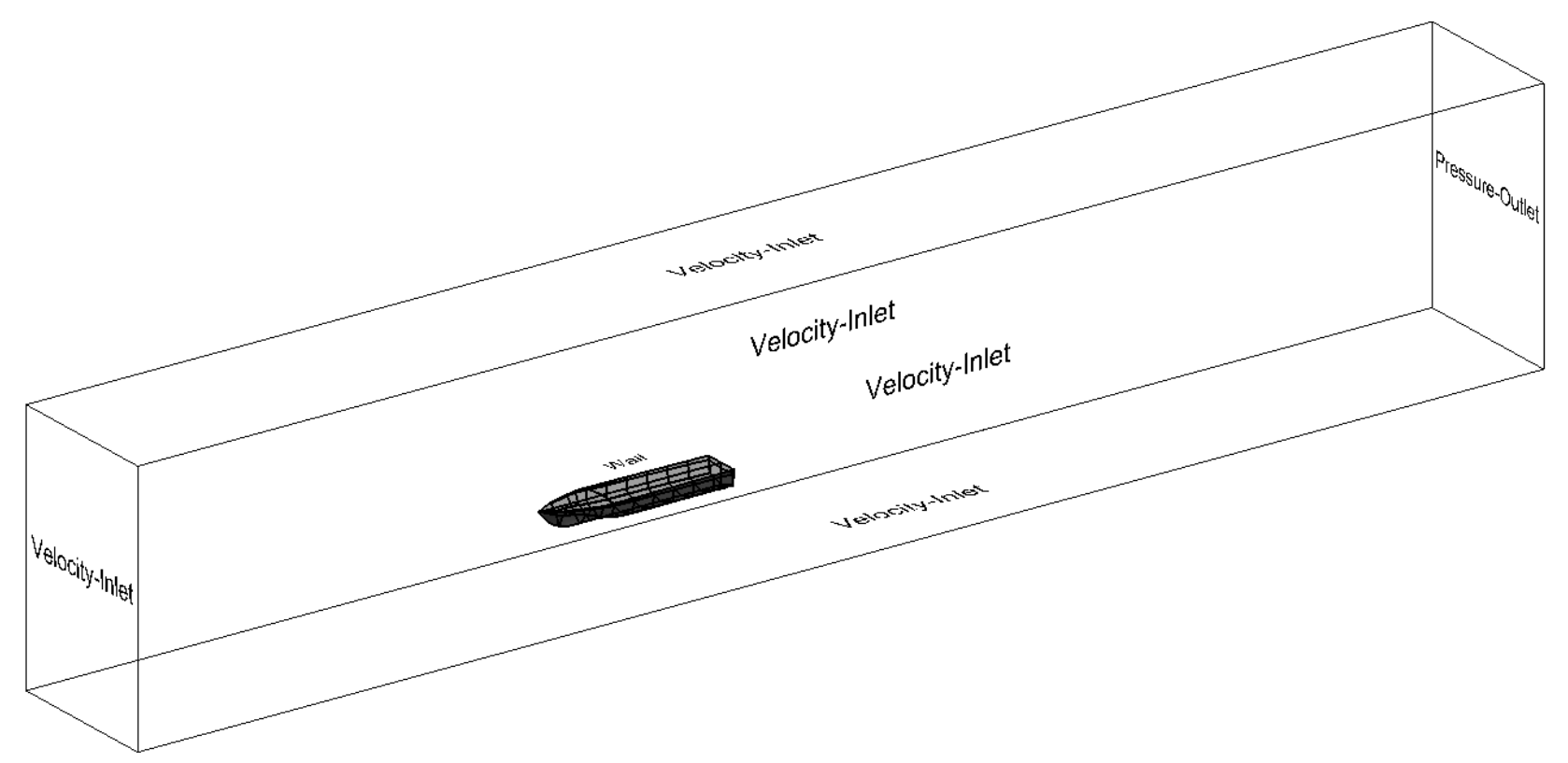

Figure 6 : Boundary conditions

\subsection{Oblique Towing Test Conditions}

The characteristics of test parameters are shown in Table 3 . The minimum and maximum values of Froude number are 0.4 
and 1.5 with an interval of 0.1 , and in two drift angles of 10 and 20 . To converging the simulation and calculate its dynamic trim and heel angles, the origin of coordinate system located on the intersection of thrust line and the perpendicular line through the center of gravity of the boat.

Table 3: Oblique towing test parameters (Katayama, 2004)

\begin{tabular}{|l|l|l|}
\hline \multicolumn{1}{|c|}{ Parameter } & \multicolumn{1}{|c|}{ Value } & \multicolumn{1}{c|}{ Unit } \\
\hline $\mathrm{Fn}_{\mathrm{L}}$ & $0.4 \sim 1.5($ step 0.1$)$ & - \\
\hline$\beta$ & 10 and 20 & degree \\
\hline
\end{tabular}

Additionally, to compare the longitudinal and lateral resistance forces, as well as the yaw moment derived from the simulations with the experimental results, the following Equations (7) to (9) are used to obtain the non-dimensional coefficients.

$$
\begin{gathered}
C_{f x}=\frac{F_{x}}{0.5 \rho S_{y} U^{2}} \\
C_{f y}=\frac{F_{y}}{0.5 \rho S_{y} U^{2}} \\
C_{M z}=\frac{M_{z}}{0.5 \rho S_{y} L_{O A} U^{2}}
\end{gathered}
$$

\section{RESULTS AND DISCUSSIONS}

The results of the simulation have been compared with the experimental results (Katayama, 2004). First, the variations of the resistance, coefficients of the forces and the moment have been shown for a better understanding of the problem, then, the magnitudes of dynamic trim and heel angles' variations as well as the dynamic sinkage due to applied hydrodynamic forces have been calculated; and finally, the hydrodynamic coefficients of the boat have been extracted.

\subsection{Resistance and Coefficients of the Forces and the Moment}

The variations of the resistance in zero drift angle versus the longitudinal Froude number have been compared with experimental results (Figure 7). It can be seen that the results have a good correlation with the model tests. The maximum error for resistance predicted by the simulation is less than $\% 7.2$ compared to the experimental results. 


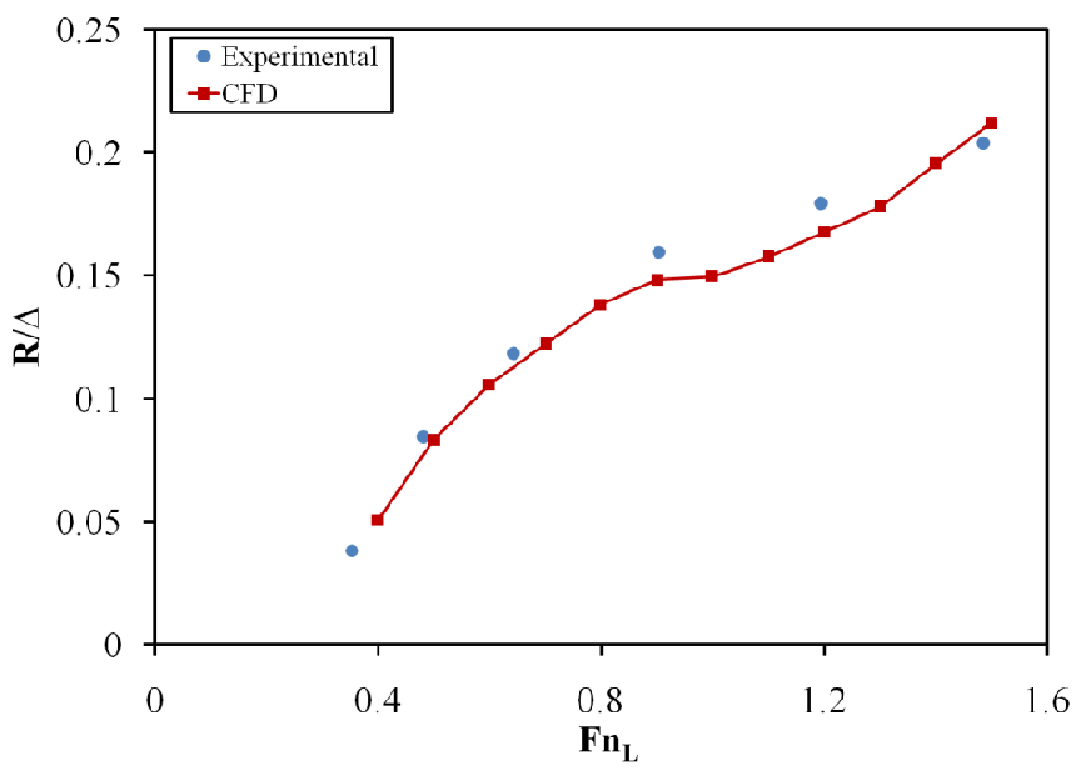

Figure 7: Comparison of resistance between experimental and CFD results in various Froude numbers

The coefficient of longitudinal resistance force (Figure 8) for different drift angles has its maximum value in Froude number of 0.5 and afterward, due to increasing the Froude number, the coefficient decreases by further increase of the Froude number. It decreases about $\% 25, \% 16$ and $\% 14$ of its maximum value in each drift angles of zero, 10 and 20 , respectively. Also, for longitudinal Froude numbers less than 0.5, this coefficient increases with increase of drift angles.

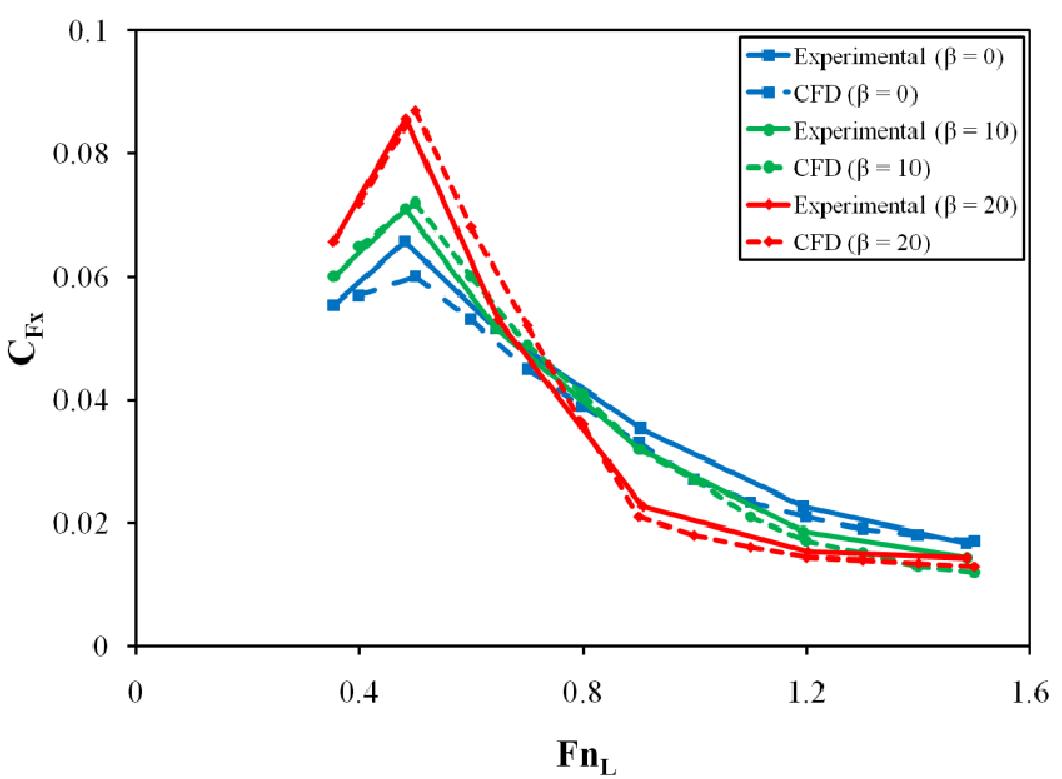

Figure 8: Coefficient of longitudinal resistance force versus $\mathrm{Fn}_{\mathrm{L}}$ in different drift angles

The coefficients of lateral resistance force are shown in Figure 9. Since the variation of this coefficient is negligible in zero drift angle, it has been withdrawn. Like the longitudinal resistance force, lateral force has its maximum 
value in Froude number of 0.5 in different drift angles; it decreases due to increasing the Froude number and for the maximum Froude number, it decreases to $\% 40$ and $\% 25$ of its maximum value in drift angles of 10 and 20 , respectively. Diagrams show that the lateral resistance force increases greatly with drift angle and in 20 degrees, this coefficient is about 2.7 times for the case with the drift angle of in 10 degrees. Whereas, the coefficient of the longitudinal resistance force in drift angle of 20 degrees, is 0.9 times its value in 10 degrees.

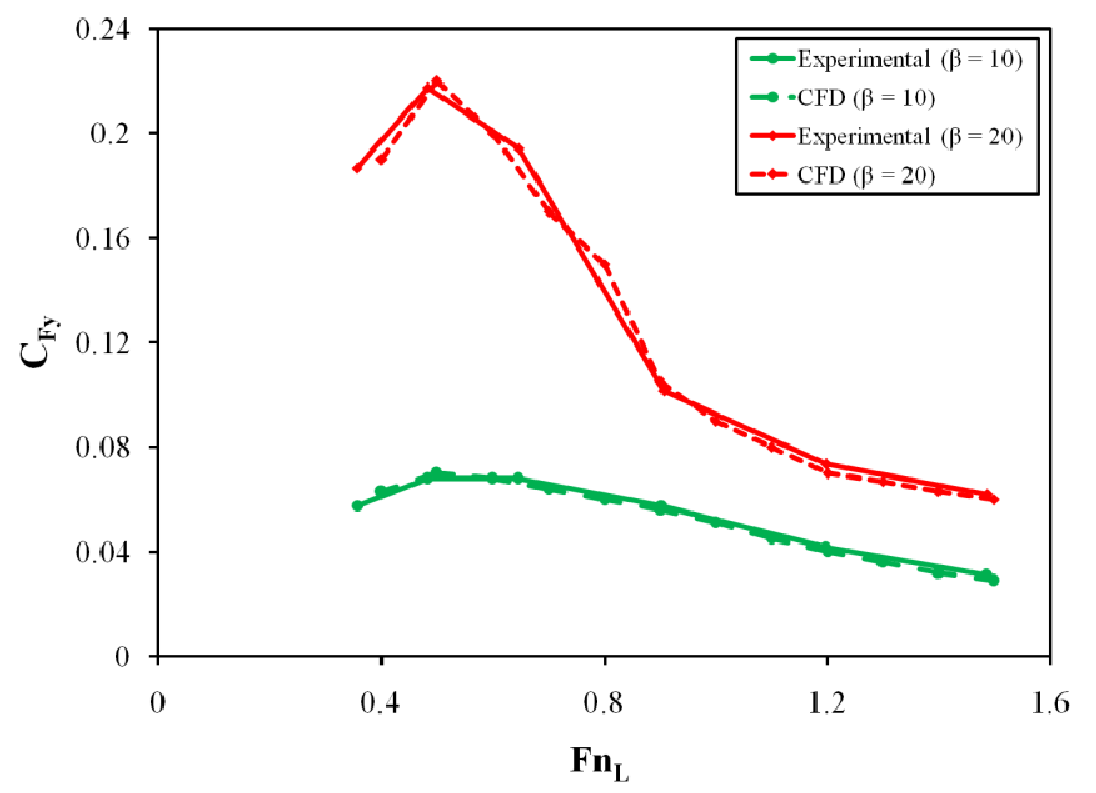

Figure 9: Coefficient of Lateral resistance force versus. $\mathrm{Fn}_{\mathrm{L}}$ in different drift angles

For the drift angle of 10 degrees, the lateral resistance force is 1.8 times of the longitudinal one on average, while in the drift angle of 20 degrees, the lateral force, especially for the Froude numbers less than 0.5 is 4 times of the longitudinal force which has effects on yaw moment as shown in Figure 10. Considering Figure 10, the coefficient of yaw moment for Froude numbers less than 0.5, in drift angle of 20 degrees is three times larger than its value in 10 degrees in same range of Froude number, because, in this drift angle, the lateral resistance force dominants the longitudinal one. 


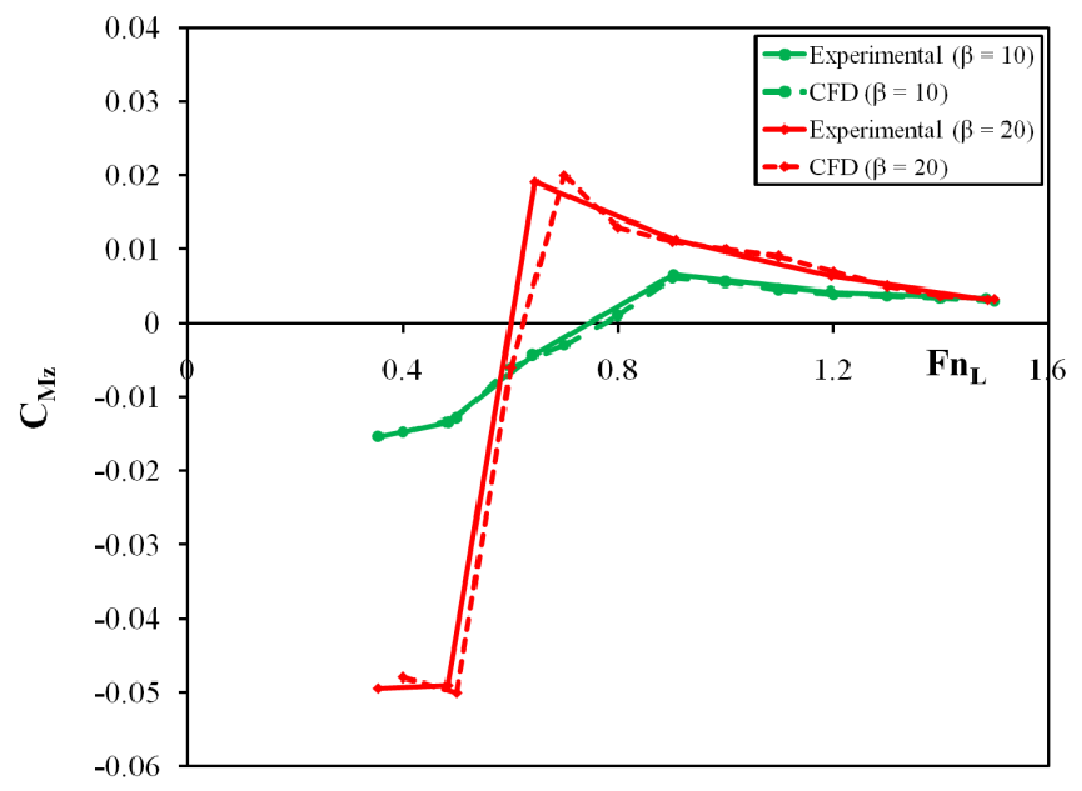

Figure 10: Coefficient of yaw moment versus $\mathrm{Fn}_{\mathrm{L}}$ in different drift angles

As the coefficient of yaw moment is negligible in drift angle of zero (because the very small value of lateral resistance force), it has been overlooked. The comparison in Figure 10 shows that for longitudinal Froude numbers less than 0.8 , the drift angle influences on the yaw moment, whereas its effects become low for the larger longitudinal Froude number.

\subsection{Dynamic Trim, Heel and Sinkage}

The variations of dynamic trim and heel angles as well as dynamic sinkage versus longitudinal Froude number in various drift angles, have been investigated. The dynamic heel angle in drift angle of zero is very close to zero due to the very small lateral resistance force. As shown in Figure 11, dynamic trim angle varies between 0.65 and 4.8 degrees. The maximum value of this angle occurs in a particular longitudinal Froude number regarding to its drift angle; so that, the maximum of this parameter occurs in Froude numbers of 0.9 and 0.6 in drift angles of zero, 10 and 20, respectively. 


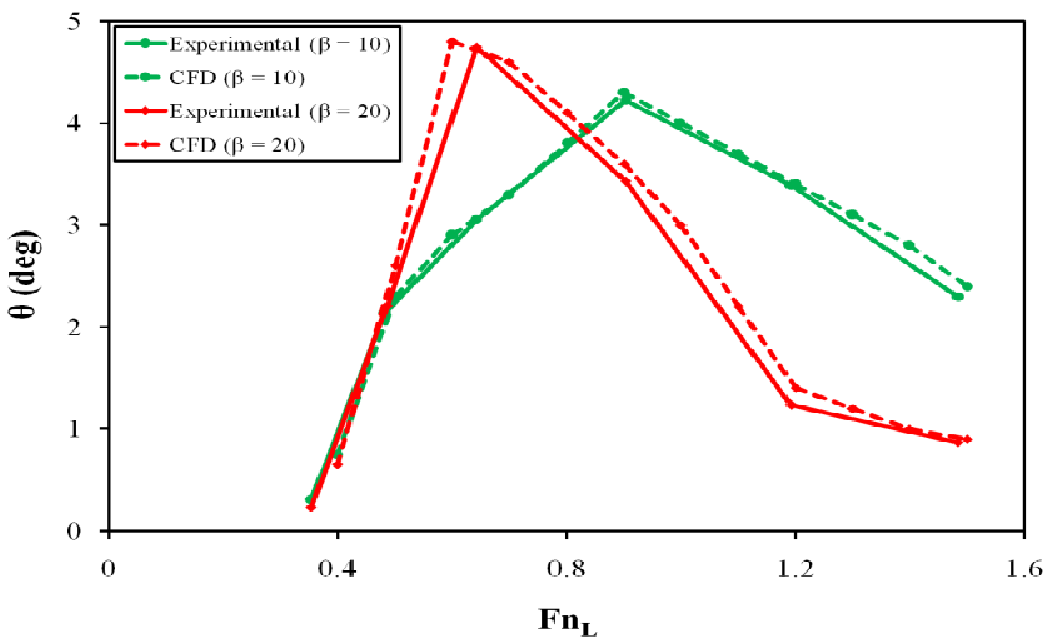

Figure 11: Dynamic trim angle versus $F_{L}$ in different drift angles

Figure 12 illustrates the dynamic heel angle versus longitudinal Froude number in drift angles of 10 and 20 degrees. In drift angle of 10 degrees, the dynamic heel angle increases by increasing the longitudinal Froude number. Through the taken oblique towing tests, the maximum dynamic heel angle of 22.94 degree in drift angle of 20 occurs in longitudinal Froude number of 0.9. In drift angle of 20 degree, for longitudinal Froude numbers less than 0.9 , this parameter increases with the Froude number, but after that it decreases.

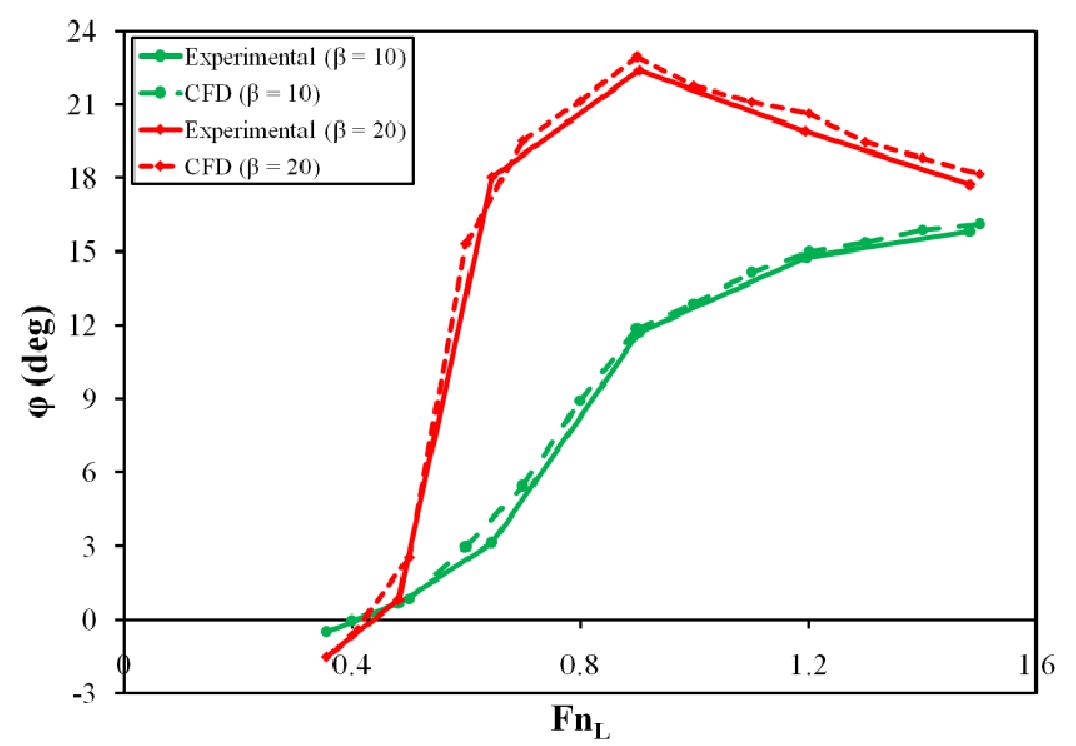

Figure 12: Dynamic heel angle versus $\mathrm{Fn}_{\mathrm{L}}$ in different drift angles

Figure 13 represents the variations of the dynamic sinkage of the boat versus longitudinal Froude number in different drift angles. According to this figure, for Froude numbers greater than 0.8 , dynamic sinkage increases with drift angle; whereas, in Froude numbers less than 0.6, this parameter in drift angle of 10 degrees is smaller. In drift angle of 20 
degrees (Figure 13), the variation rate of the dynamic sinkage for Froude numbers greater than 0.8 is on average $\% 14$ of the variation rate of this parameter in Froude numbers less than 0.8. Also, this rate is extremely high in Froude number less than 0.6 .

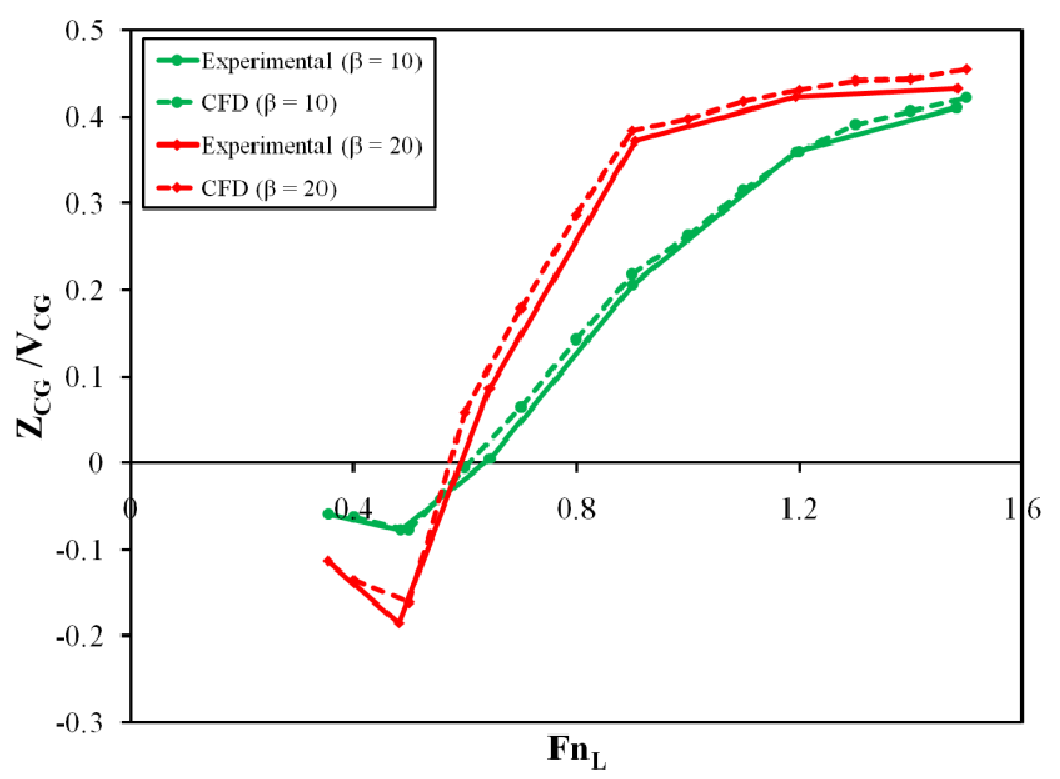

Figure 13: Dynamic sinkage versus $\mathrm{Fn}_{\mathrm{L}}$ in different drift angles

\subsection{Hydrodynamic Coefficients}

The aim of experimental test or numerical simulation of oblique towing test on a boat is to extract the hydrodynamic coefficients to solve the maneuver equations of a boat. To extract the hydrodynamic coefficients, the forces and moment variations versus speed must be calculated. In this study, two coefficients of $\mathrm{Y}_{\mathrm{v}}$ and $\mathrm{N}_{\mathrm{v}}$ are calculated by simulating the oblique towing test. These coefficients are actually the first-order of damping coefficients of maneuvering equations. The variations of sway force and yaw moment versus speed are shown in Figure 14 and Figure 15.

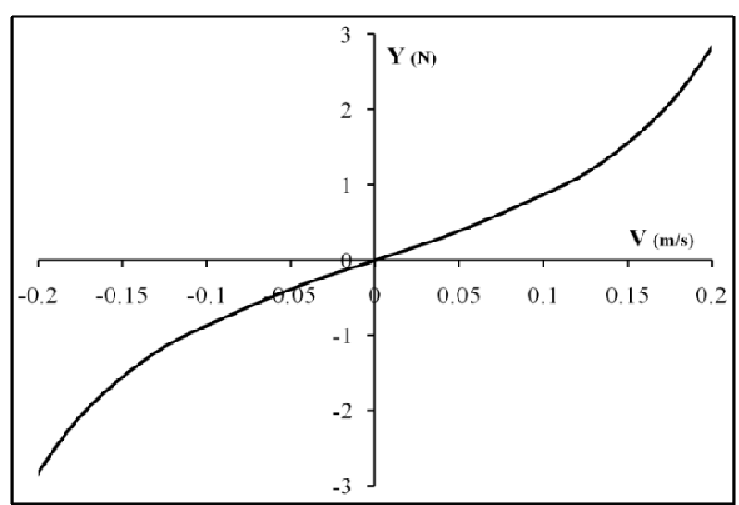

Figure 14 : Variations of sway force of boat versus speed

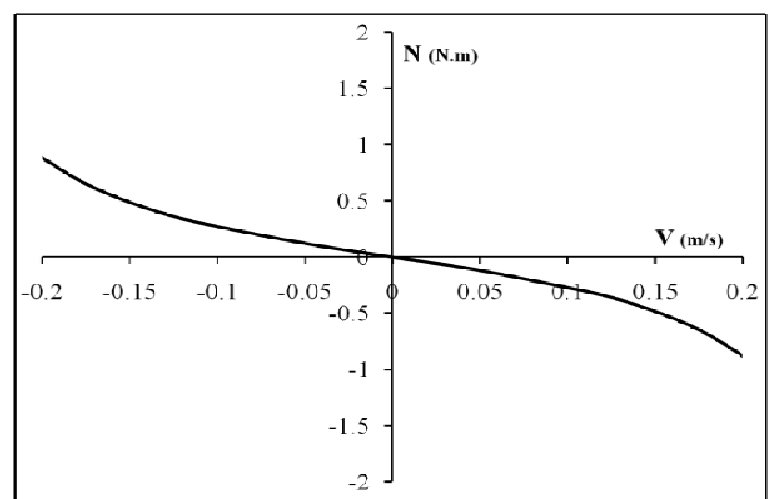

Figure 15 : Variations of yaw moment of boat versus speed 
The hydrodynamic coefficients of these force and moment are calculated as follow:

$Y_{V}=\left.\frac{\partial Y}{\partial V}\right|_{V=0}$

$N_{V}=\left.\frac{\partial N}{\partial V}\right|_{V=0}$

These equations are derivative of the sway force and yaw moment at zero speed and their values are listed in Table 4.

Table 4: The values of the coefficients

\begin{tabular}{|l|l|l|}
\hline \multicolumn{1}{|c|}{ Coefficient } & \multicolumn{1}{|c|}{ Value } & \multicolumn{1}{c|}{ Unit } \\
\hline $\mathrm{Y}_{\mathrm{v}}$ & 7.54 & $\mathrm{~N} \mathrm{~s} / \mathrm{m}$ \\
\hline $\mathrm{N}_{\mathrm{v}}$ & 2.36 & $\mathrm{Nm} \mathrm{s} / \mathrm{m}$ \\
\hline
\end{tabular}

Here the results of the simulation for Froude number of 1.2 in drift angle of 10 degree has been represented as a sample of the simulation; so, dynamic heel, wetted area and streamlines on free surface have been shown in Figure 16, Figure 17 and Figure 18, respectively.

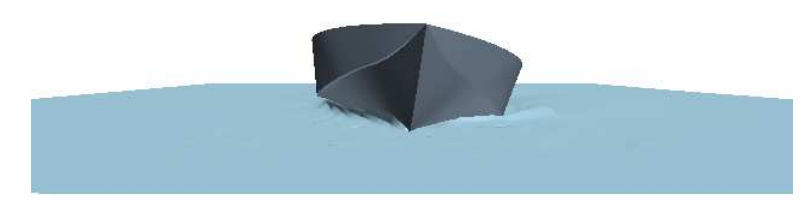

Figure 16 : Dynamic heel in drift angle of 10 degree and $\mathrm{Fn}_{\mathrm{L}}$ of 1.2

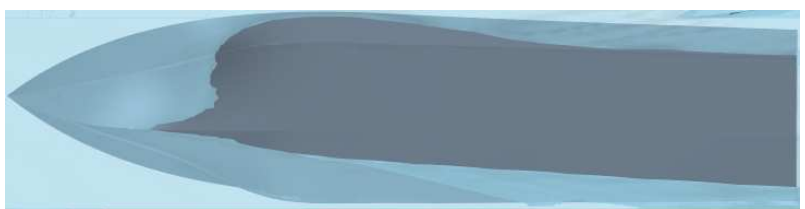

Figure 17 : Wetted area in drift angle of 10 degree and $\mathrm{Fn}_{\mathrm{L}}$ of 1.2

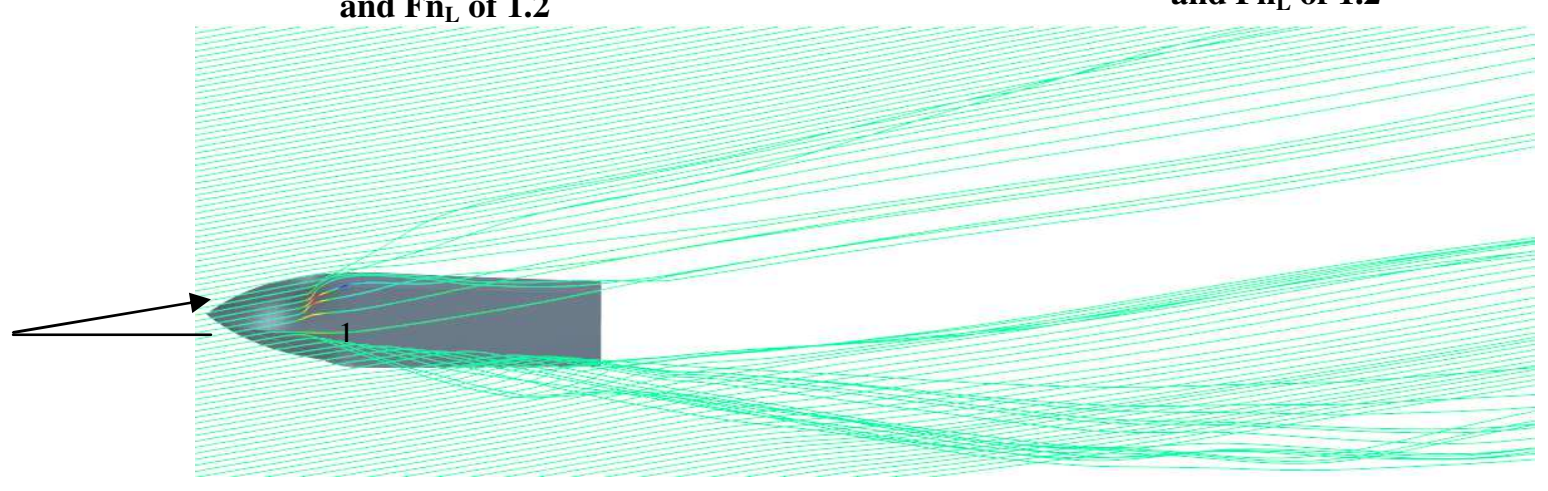

Figure 18 : Streamline in drift angle of 10 degrees and $\mathrm{Fn}_{\mathrm{L}}$ of 1.2

\section{CONCLUSIONS}

The maneuverability of a high-speed craft can be investigated by accurate mathematical models. These models include, the hydrodynamic forces and moments which are expressed as hydrodynamic coefficients. Hence, to solve these equations, the hydrodynamic coefficients should be determined. The aim of experimental test or numerical simulation of oblique towing 
test of a boat is to extract the hydrodynamic coefficients to solve the maneuver equations. In this study, the oblique towing test has been dynamically simulated by CFD method on a high-speed boat model in drift angles of 10 and 20 degrees with three degrees of freedom by means of dynamic mesh technique. The coefficients of longitudinal and lateral resistance force, as well as yaw moment have been computed. The results show that the coefficient of longitudinal resistance force for longitudinal Froude numbers before 0.6 increases with drift angle increment, and for Froude numbers greater than 1.2 reverses its trend. The lateral resistance force increases significantly and in drift angle of 20 degrees, the lateral resistance coefficient increases to 2.7 times its value in drift angle of 10 degree. In longitudinal Froude numbers before 0.8 , the drift angle is affected on yaw moment while afterward; its effects on yaw moment become negligible.

\section{REFERENCES}

1. M. Bagherzadeh, et al, (2014). Wave wash prediction of the river craft using numerical approach. X HSMV.

2. M. Bagherzadeh, et al, (2015). Selection of suitable methods and tools for analyzing dynamic behavior of planing crafts in calm water. $4^{\text {th }}$ National Conference on Fast Crafts.

3. M. Bagherzadeh, et al, (2019) (a). Proper meshing for numerical simulation of high speed craft in rough water. $6^{\text {th }}$ National Conference on Fast Crafts.

4. M. Bagherzadeh, et al, (2019) (b). The effect of selection of time-step in simulation of high speed crafts. $6^{\text {th }}$ National Conference on Fast Crafts.

5. H. Hajivand, S. H. Mousavizadegan, (2015). Virtual maneuvering test in CFD media in presence of free surface. Int. J. Nav. Archit. Ocean Eng. (7:540-558), 2.

6. S. Hajizadeh, et al, (2017). Evaluation of planing craft maneuverability using mathematical modeling under the action of the rudder" Scientia Iranica B, 24(1), (293-301).

7. ITTC, 2011, Recommended Procedures and Guidelines Practical Guidelines for Ship CFD Applications 7.5-03-02-03, 3, 5, 7.

8. E. Jahanbakhsh, et al, (2008). Catamaran motion simulation based on moving grid technique" Journal of Marine Science and Technology, 17(2), (128-136), 2.

9. M. R. Javanmardi, et al, (2008). Trimaran maneuvering simulation based on a three-dimensional viscous free surface flow solver" Proceeding of $6^{\text {th }}$ International Conference on High-Performance Marine Vehicles (HIPER'08), (249-256), 2.

10. T. Katayama, Y. Ikeda, (1999). Hydrodynamic forces acting on porpoising craft at high-speed. Journal of Ship and Ocean Technology, the Society of Naval Architects of Korea, Vol.3, No.2, (17-26), 1.

11. T. Katayama, (2004). Effects of Running Attitude on Hydrodynamic Forces for Oblique Towed Planing Craft. APHydro, (115$122), 2,4,8$.

12. T. Katayama, Y. Ikeda, (1995). An Experimental Study on Transverse Stability Loss of planing Craft at High Speed in Calm Water. Journal of the Kansai Society of Naval Architects, No.224, (77-85).

13. T. Katayama, et al, (2009). Development of maneuvering simulation method for high speed craft using hydrodynamic forces obtained from model tests. 10 International Conference on Fast Sea Transportation. 
14. D. Marco, et al, (2017). Experimental and numerical hydrodynamic analysis of a stepped planning hull. Ocean Research 64, (135-154).

15. H. Nikoosirat, et al, (2019) (a). Numerical simulation of rotating arm test of planing craft. The $6^{\text {th }}$ National Conference on Fast Crafts.

16. H. Nikoosirat, et al, (2019) (b). Numerical simulation of zig-zag maneuvering test of planing craft. The $6^{\text {th }}$ National Conference on Fast Crafts. 